\title{
Apropos use of biological mesh in trans-anal treatment for recurrent recto-urethral fistula
}

\author{
Deepak Batura ${ }^{1} \oplus$
}

Received: 2 August 2017 / Accepted: 11 September 2017 / Published online: 16 September 2017

(C) Springer Science+Business Media B.V. 2017

Editor,

Moretto et al. are to be congratulated on their novel and innovative method of repair of post-radical prostatectomy recto-urethral fistulas, described in their paper: Use of biological mesh in trans-anal treatment for recurrent recto-urethral fistula [1]. A difficult condition to treat with frequent recurrence, their minimally invasive method should hold great promise.

However, the paper does raise a few queries about their technique and outcomes. As these fistulas are clean contaminated at best, and most likely infected at worst, it is surprising that the authors relied only upon 6 days of ciprofloxacin prophylaxis to prevent mesh infection. For instance, they do not mention whether any enteric preparation or mechanical bowel cleaning was employed beforehand. Enteric preparation of some sort is a standard recommendation for anorectal surgery [2].

The authors note no recurrence or complications over a median follow-up of nearly 3 years. However, the literature mentions a high rate of recurrences and infective complications (sepsis, suppuration, or abscesses) following the use of such devices in anorectal conditions [3, 4]. It is not unreasonable to expect some of these complications or recurrences when the plug is being used in a recto-urethral repair as well. Therefore, it becomes necessary to know whether any bacteriological studies were carried out during followup. Certainly, it might be worth considering whether a study

Deepak Batura

deepakbatura@gmail.com

1 Department of Urology, London North West Healthcare NHS Trust, Watford Road, Harrow, London HA1 3UJ, UK with a greater number of patients and with longer follow-up might yield different outcomes.

In addition, the authors do not mention whether they inspected the urethra endoscopically for stricture or stone during the follow-up period. Indeed, during follow-up, did patients present with lower tract urinary symptoms that might indicate infective or urethral sequelae?

Compliance with ethical standards

Conflict of interest The author declares that he has no conflict of interest and that no funding has been received toward writing this manuscript.

Human and animal rights statement This article does not contain any studies with human participants or animals.

\section{References}

1. Moretto G, Casaril A, Inama M (2017) Use of biological mesh in trans-anal treatment for recurrent recto-urethral fistula. Int Urol Nephrol. doi:10.1007/s11255-017-1652-5

2. Mangram AJ, Horan TC, Pearson ML, Silver LC, Jarvis WR (1999) Guideline for Prevention of Surgical Site Infection, 1999. Centers for Disease Control and Prevention (CDC) Hospital Infection Control Practices Advisory Committee. Am J Infect Control 27(2):97-132

3. Garg P, Song J, Bhatia A, Kalia H, Menon GR (2010) The efficacy of anal fistula plug in fistula-in-ano: a systematic review. Colorectal Dis 12:965-970

4. Ortiz H, Marzo J, Ciga MA, Oteiza F, Armendáriz P, de Miguel M (2009) Randomized clinical trial of anal fistula plug versus endorectal advancement flap for the treatment of high cryptoglandular fistula in ano. Br J Surg 96:608-612 